\title{
Health awareness improvement through hand washing with soap with elementary school students at Tongging village
}

\author{
Herli Ginting $^{1 *}$, Grace Patricia Nauli Basa Simatupang ${ }^{2}$, Khairunnisa Rangkuti ${ }^{1}$ \\ ${ }^{1}$ Faculty of Mathematics and Natural Science, Universitas Sumatera Utara, Medan, Indonesia \\ ${ }^{2}$ Faculty of Public Health, Universitas Sumatera Utara, Medan, Indonesia \\ *Email: Herli1@usu.ac.id
}

\begin{abstract}
Health behavior problems in school-age children are related to personal hygiene and the environment. One of the health problems is the lack of awareness of washing hands with soap. The purpose of this study was to determine the knowledge of elementary students in the Tongging village, Mako district. This type of research is qualitative research that intends to understand the phenomena about what is experienced by research subjects such as behavior, perception, motivation, ways of description in the form of words and language, in a special natural context and by utilizing various natural methods. The sample of this research is students of SD Negeri 044845 Tongging village, Kecamatan Karo district. The results showed that the majority of respondents had an increase in health-conscious knowledge through proper and proper hand washing.
\end{abstract}

Keyword: KKN-PPM, Counseling, Wash Hands with Soap

\begin{abstract}
Abstrak
Permasalahan perilaku kesehatan pada anak usia sekolah berkaitan dengan kebersihan perorangan dan lingkungannya. Salah satu pemasalahan kesehatan yaitu kurangnya kesadaran terhadap cuci tangan pakai sabun. Tujuan penelitian ini adalah untuk mengetahui pengetahuan siswa-siswi sekolah dasar desa Tongging kecamatan Merek kabupaten Karo. Jenis penilitian ini adalah kualitatif penelitian yang bermaksud memahami fenomena tentang apa yang dialami oleh subjek penelitian misalnnya perilaku, presepsi, motivasi, cara deskripsi dalam bentuk kata-kata dan bahasa, pada suatu konteks khusus yang alamiah dan dengan memanfaatkan berbagai metode alamiah. Sampel penelitian ialah siswa SD Negeri 044845 desa Tongging kecamatan Merek kabupaten Karo. Hasil penelitian menunjukkan bahwa sebagian besar responden memiliki peningkatan pengetahuan sadar kesehatan melalui cara mencuci tangan yang baik dan benar.
\end{abstract}

Kata Kunci: KKN-PPM, Penyuluhan, Cuci Tangan Pakai Sabun

\section{PENDAHULUAN}

Cuci tangan yang baik dan benar adalah menggunakan air bersih yang mengalir dan memakai sabun. Kegiatan cuci tangan pakai sabun merupakan salah satu indikator PHBS di sekolah. Peringaan cuci tangan pakai sabun 2010 mengangkat sub tema "Cuci Tangan Pakai Sabun". Perilaku sederhan berdampak luar biasa (Kemenkes RI, 2010). Permasalahan perilaku kesehatan pada anak usia sekolah biasanya berkaitan dengan kebersihan perorangan dan lingkungannya. Salah satu permasalahan karna kurangnya kesadaran terhadap cuci tangan pakai sabun adalah masalah Diare. Di duia sebanyak 6 juta anak meninggal setiap tahunnya karena diare, sebagian kematian tersebut terjadi di negara berkembang. Di perkirakan lebih dari 10 juta anak berusia kurang dari 5 tahun meninggal setiap tahunnya, sekitar 20\% meninggal karena infeksi diare (Kemenkes RI, 2011).

Persepsi dan perilaku terhadap kebiasaan mencuci tangan menemukan bahwa sabun telah sampai ke hampir setiap rumah di indonesia, namun sekitar 3\% yang menggunakan sabun untuk cuci tangan, untuk didesa angkanya bisa lebih rendah lagi. Mencuci tangan pakai sabun dapat menurunkan resiko diare hingga 50\% (WHO, 2011). Anak usia sekolah 
merupakan kelompok usia yang kritis, karena pada usia tersebut seorang anak rentan terhadap masalahkesehatan. Selain rentan terhadap masalah kesehatan, anak usia sekolah juga berada pada kondisi yang sangat peka terhadap stimulus sehingga mudah dibimbing, diarahkan, dan ditanamkan kebiasaan-kebiasaan yang baik, termasuk kebiasaan berperilaku hidup bersih dan sehat. Pada umumnya, anak-anak seusia ini juga memiliki sifat selalu ingin menyampaikan apa yang diterima dan diketahuinya dari orang lain (Nadia, 2012). Menurut Djauzi (2008), mencuci tangan merupakan salah satu cara untuk menghilangkan kuman dan untuk menghindari penularan penyakit. Di sekolah, anak tidak hanya belajar, tetapi banyak kegiatan lain seperti bermain, bersentuhan, ataupun bertukar barang-barang dengan teman-teman. Kuman yang terdapat di alat tulis, buku, dan benda lain akan mudah berpindah dari tangan satu anak ke anak lainnya, sehingga penyakit akan mudah menular. Jadi, mencuci tangan harus dilatih sejak dini pada anak agar memiliki kebiasaan mencuci tangan, sehingga anak terhindar dari penyakit.

Sekolah Dasar Negeri 044845 desa Tongging, kecamatan Merek, kabupaten Karo merupakan institusi pendidikan pada anak yang berusia dari 6-13 tahun. Sekolah Dasar Negeri 044845 desa Tongging, kecamatan Merek, kabupaten Karo dan berada dipinggir jalan yang merupakan daerah perdesaan yang cukup jauh dari kota. Berdasarkan wawancara yang dilakukan dengan kepala sekolah Ibu Saharia Sembiring beliau mengatakan masih kurangnya pendidikan kesehatan tentang mencuci tangan dan belum ada penyuluhan kesehatan tentang pentingnya mencuci tangan menggunakan sabun dari petugas kesehatan. Berdasarkan data yang di peroleh, maka kami peserta pengabdian tertarik untuk melakukan penyuluhan dengan pentingnya kesehatan cuci tangan pakai sabun di Sekolah Dasar Negeri 044845 desa Tongging, kecamatan Merek, kabupaten Karo.

\section{METODE PELAKSANAAN}

Metode pelaksanaan dalam kegiatan pengabdian kepada masyarakat ini adalah dengan menggunakan metode ceramah atau sosialisasi dan diakhir dengan melakukan praktek mencuci tangan pakai sabun. Pengabdian dilakukan di SDN Negeri 044845 desa Tongging, kecamatan Merek, kabupaten Karo pada tanggal 1 Agustus 2019. Metode yang digunakan dalam kegiatan pengabdian kepada masyarakat ini adalah dengan melakukan observasi ke SDN Negeri 044845 desa Tongging, kecamatan Merek, kabupaten Karo untuk melihat sejauh mana pentingnya kesehatan cuci tangan ini kepada siswa karena memang belum ada kegiatan serupa di lokasi pengabdian ini. Partisipasi mitra dalam kegiatan pengabdian kepada masyarakat ini yaitu seluruh warga sekolah dasar Negeri 044845 desa Tongging, bersama dengan mahasiswa KKN Universitas Sumatera Utara. Evaluasi pelaksanaan kegiatan pengabdian kepada masyarakat ini dilakukan dengan memberikan pengarahan tentang hidup sehat yang dimulai dari kegiatan mencuci tangan yang biasa dilakukan dari rumah dan setiap kegiatan di sekolah. Keberhasilan kegiatan pengabdian ini diukur dari antusias para siswa yang mengikuti kegiatan, adanya respon positif dari kepala sekolah dan juga keaktifan siswa siswi SDN 044845 desa Tongging untuk mempraktekan kegiatan cuci tangan pakai sabun dan setelah memberikan materi dan arahan kepada siswa-siswi tersebut demi mengetahui sejauh mana siswa-siswi tersebut memahami tentang materi yang sudah dibahas, mahasiswa/I yang memberikan materi kepada siswa-siswi tersebut mengajak untuk melakukan beberapa games yang mana tujuan dari games tersebut adalah untuk megetahui sejauh mana siswa-siswi tesebut memahami tentang materi-materi yang sudah diberikan oleh pemateri.

\section{HASIL DAN PEMBAHASAN}

Dari kegiatan yang kami lakukan kami memilih untuk melakukan penyuluhan CTPS yaitu 7 langkah cuci tangan yang baik dan benar bagi siswa-siswi karna sangat berguna bagi mereka yang masih belum tau dan paham bahwa mencuci tangan sangat bermanfaat bagi kesehatan. Kegiatan penyuluhan ini merupakan salah satu kegiatan program kerja KKN kelompok 4 di desa Tongging 
kecamatan Merek, kabupaten Karo. Kegiatan ini dilaksanakan SDN 044845 desa Tongging tepatnya di dusun 2. Subjek dari kegiatan yaitu siswa-siswi kelas 1 sampai kelas 6 yang terdiri dari yang total keseluruhan kelas berjumlah 185 orang.

Saat melakukan kegiatan 7 langkah cuci tangan yang baik dan benar anak-anak sangat antusias dalam kegiatan ini. Mereka mengikuti setiap langkah-langkah cuci tangan yang baik dan benar, sampai saat disuruh kedepan mereka semua mengangkat tangan untuk maju kedepan mempraktekan 7 langkah cuci tangan yang benar didepan sesuai yang sudah diajarkan oleh kami peserta KKN kelompok 4, mereka dapat mengikuti kami karna metode yang kami ajarkan adalah belajar sambil bermain dan bernyanyi serta diikuti dengan gerakan dan musik sebagai penyemangat kegiatan penyuluhan yang kami lakukan agar siswa-siswi SDN 044845 itu tidak merasakan bosan melakukan kegiatan penyuluhan tersebut. Bermain yang kami maksud disini acara tambahan yang kami selingi di sela-sela acara kegiatan penyuluhan dengan gerakan yang lucu dan musik yang menarik perhatian anak-anak tersebut, sehingga mereka semua sangat menyukai dan dapat mengikuti acara kegiatan ini dengan baik dan kami harapkan bisa menerapkannya dalam kehidupan sehari-hari agar menjauhkan dan menghindari diri mereka untuk terserang penyakit seperti sakit perut karena diare, dan lain sebagainya. Dibawah ini terdapat dokumentasi saat kami kelompok 4 melaksanakan kegiatan penyuluhan yang dilakukakan pada siswa-siswi kelas 1samai kelas 6 di SDN 044845 desa Tongging kecamatan Merek.

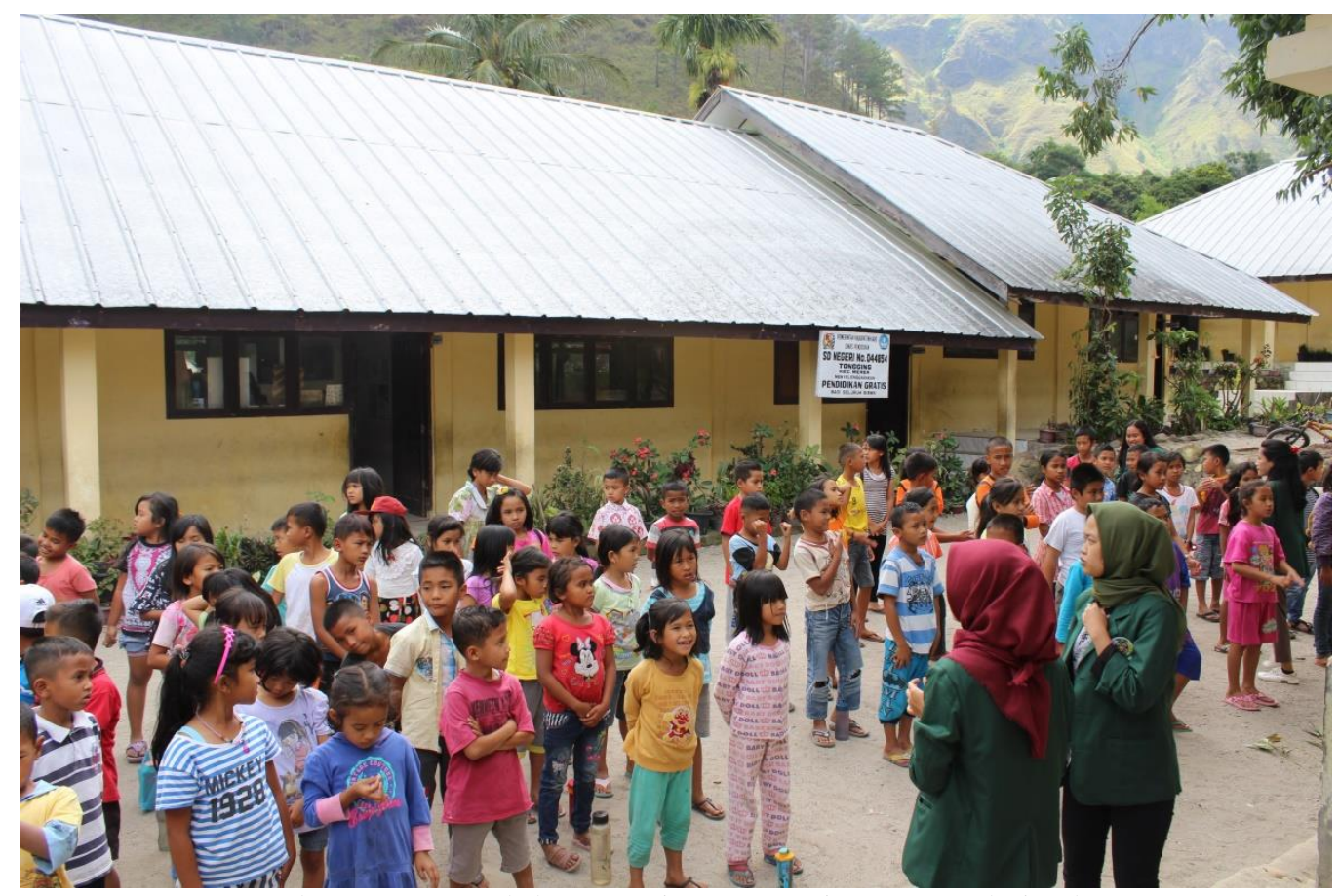

Gambar 3.1 Penyuluhan pentingnya cuci tangan pakai sabun 


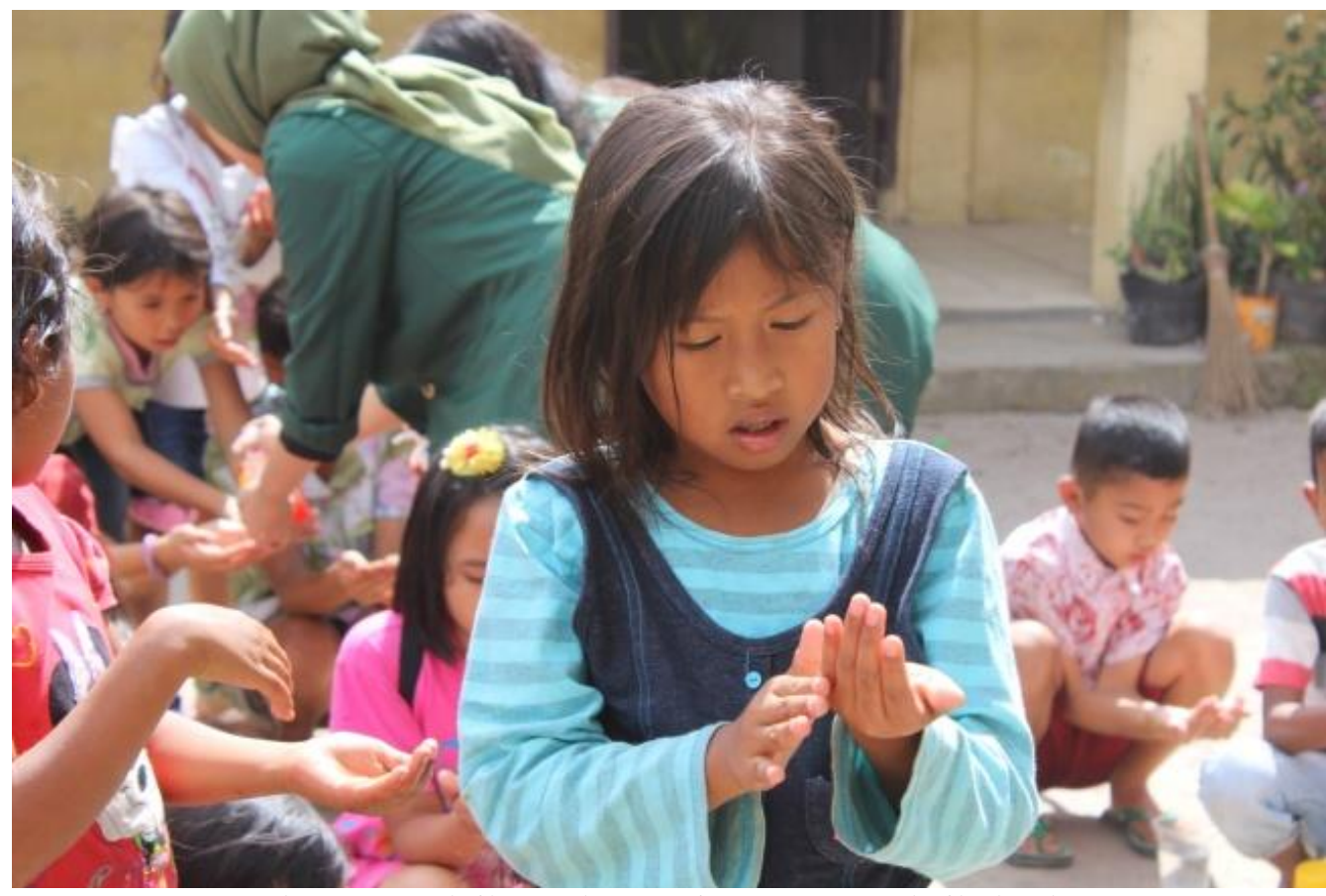

Gambar 3.2 Praktik gerakan cuci tangan yang baik dan benar

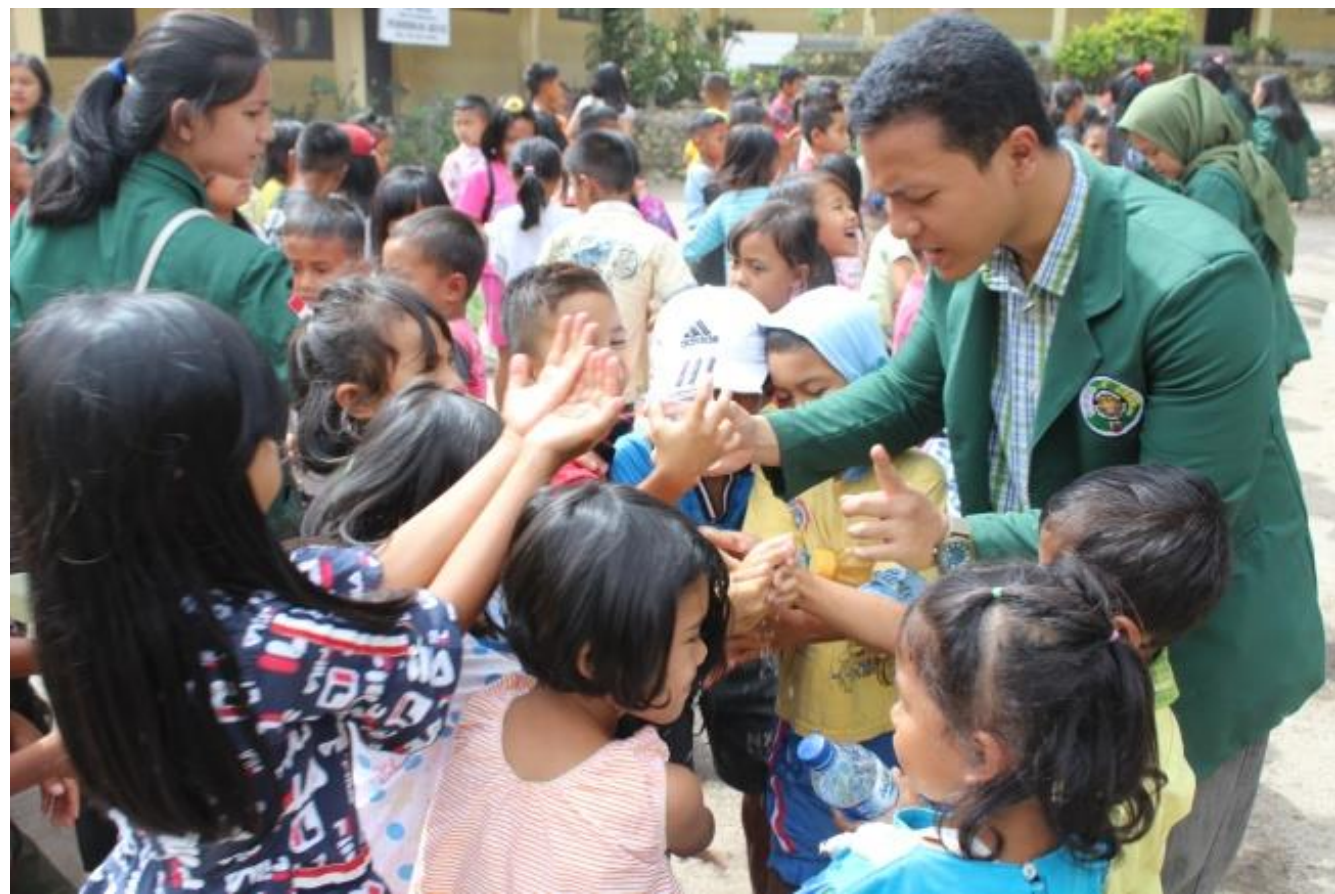

Gambar 3.3 Respon positif para siswi-siswi dalam melakukan gerakan cuci tangan pakai sabun

\section{KESIMPULAN}

Secara keseluruhan kegiatan penyuluhan CTPS berjalan dengan lancar. Jika ada kegiatan penyuluhan kesehatan seperti ini bisa dilakukan lebih baik lagi dan mempersiapkan segala bentuk dari kegiatan penyuluhan CTPS ini yang sangat penting dan bermanfaat bagi kesehatandan diharapkan dengan adanya kegiatan seperti ini diharapkan kepada sekolah dan seluruh orang tua murid untuk dapat lebih mengajarkan kepada anak-anak mereka untuk menjaga kebersihan tangan agar anak-anak dapat terhindar dari segala macam penyakit dan pentingnya menjaga 
kebersihan lingkungan sekitar agar nyaman dan bersih. Terimakasih kepada bapak M Fajar Anugerah S.IP., M.Siselaku dosen pembimbing lapangan, kepada kepala sekolah SDN 128 kecamatan rumbai kelurahan rantau panjang pekanbaru yakni Bapak Paisal Rusdianto S.Pd,guruguru dan seluruh staff SDN 128 kecamatan rumbai kelurahan rantau panjang yang telah mengizinkan kami dan mendukung kami dalam kegiatan penyuluhan sehingga kegiatan ini berjalan dengan baik

\section{UCAPAN TERIMAKASIH}

Tim pengabdian pada masyarakat mengucapkan terima kasih kepada Bapak Prof. Tulus, Vor. Dipl. Math. MSi, Ph.D selaku ketua LPPM USU, Bapak Dr. Kerista Sebayang selaku Dekan FMIPA USU dan pemberi dana NON PNBP 2019, tak lupa pula para staf dan pegawai LPPM, para aparat Desa Tongging, Kecamatan Merek Kabupaten Karo, Provinsi Sumatera Utara, serta para mahasiswa KKN Reguler kelompok 4 yang telah ikut serta mensukseskan pengabdian masyarakat ini.

\section{DAFTAR PUSTAKA}

Djauzi, S. 2008. Raih Kembali Kesehatan Mencegah Berbagai Penyakit Hidup Sehat Untuk Keluarga. Jakarta: Kompas.

Kementerian Kesehatan RI. Jakarta: Cuci Tangan Pakai Sabun (CTPS),Perilaku Sederhana yang Berdampak Luas Biasa; 2011 http://depkes.go.id/index.php/ berita/pressrelease /2086.html.

Kementerian Kesehatan RI. Jakarta. Peraturan Menteri Kesehatan Republik Indonesia Nomor 3 tahun 2014 tentang Sanitasi Total Berbasis Masyarakat (STBM); 2010

Kementerian Kesehatan RI. Jakarta. Perilaku Mencuci Tangan Pakai Sabun di Indonesia; 2014

Nadia, (2012). Hubungan pelaksanan program usaha kesehatan sekolah terhadap perilaku hidup bersih dan sehat pada siswa SDN 13 seberang padang utara tahun 2012. Universitas Andalas : Padang.

Proverawati, A. dan Rahmawati, E. Perlaku Hidup Bersih dan Sehat. Yogyakarta: Nuha Medika; 2012

Tim LPPMP. 2019. Kumpulan Makalah Pembekalan Kuliah Kerja Nyata (KKN) USU. Medan: Lembaga Penelitian dan Pengabdian kepada Masyarakat Universitas Sumatera Utara

Yuliana, Eva. 2016. PENDIDIKAN. [Online]. Tersedia: https://www.google.com/ amp/s/ guruppkn.com/pentingnya-pendidikan-bagi-manusia/amp. 